Article

\title{
Evaluation of Orbit, Clock and Ionospheric Corrections from Five Currently Available SBAS L1 Services: Methodology and Analysis
}

\author{
Zhixi Nie $^{1,2}$, Peiyuan Zhou ${ }^{2, *}$, Fei Liu ${ }^{2}$, Zhenjie Wang ${ }^{1}$ and Yang Gao ${ }^{2} \mathbb{C}$ \\ 1 School of Geosciences, China University of Petroleum, Qingdao 266580, China; niezhixilib@126.com (Z.N.); \\ sdwzj@upc.edu.cn (Z.W.) \\ 2 Schulich School of Engineering, University of Calgary, Calgary, AB T2N 1N4, Canada; \\ liu19@ucalgary.ca (F.L.); ygao@ucalgary.ca (Y.G.) \\ * Correspondence: peiyuan.zhou@ucalgary.ca; Tel.: +1-(587)-973-1500
}

Received: 28 December 2018; Accepted: 5 February 2019; Published: 17 February 2019

\begin{abstract}
To meet the demands of civil aviation and other precise navigation applications, several satellite-based augmentation systems (SBASs) have been developed around the world, such as the Wide Area Augmentation System (WAAS) for North America, the European Geostationary Navigation Overlay Service (EGNOS) for Europe, the Multi-functional Satellite Augmentation System (MSAS) for Japan, the GPS (Global Positioning System) Aided GEO Augmented Navigation (GAGAN) for India, and the System for Differential Corrections and Monitoring (SDCM) for Russia. The SBASs broadcast messages to correct satellite orbit, clock, and ionosphere errors to augment the GPS positioning performance. In this paper, SBAS orbit, clock and ionospheric corrections are evaluated. Specifically, the orbit, clock and ionospheric corrections derived from SBAS messages are comprehensively evaluated using data collected from the above mentioned systems over 181 consective days. The evaluation indicates that the EGNOS outperforms other systems with signal-in-space range error (SISRE) at $0.645 \mathrm{~m}$ and ionospheric correction accuracy at $0.491 \mathrm{~m}$, respectively. Meanwhile, the accuracy of SDCM is comparable to EGNOS with SISRE of $0.650 \mathrm{~m}$ and ionospheric correction accuracy of $0.523 \mathrm{~m}$. For WAAS, the SISRE is $0.954 \mathrm{~m}$ and the accuracy of ionospheric correction is $0.505 \mathrm{~m}$. The accuracies of the SBAS corrections from the MSAS and GAGAN systems, however, are significantly worse than those of others. The SISREs are 1.931 and $1.325 \mathrm{~m}$ and the accuracies of ionospheric corrections are 0.795 and $0.858 \mathrm{~m}$, for MSAS and GAGAN, respectively. At the same time, GPS broadcast orbit, clock and ionospheric corrections are also evaluated. The results show that there are no significant improvements in the SISRE of the broadcast navigation data by applying SBAS corrections. On the other hand, the accuracy of SBAS ionospheric corrections is still much better than GPS broadcast ionospheric corrections, which could still be beneficial for single-frequency users.
\end{abstract}

Keywords: SBAS; WAAS; EGNOS; MSAS; GAGAN; SDCM; orbit correction; clock correction; ionospheric correction

\section{Introduction}

In order to enhance the positioning performance of Global Positioning System (GPS) for civil aviation users, the International Civil Aviation Organization (ICAO) began studies on complementary systems from the 1990s to augment GPS in terms of accuracy, integrity, continuity, and availability. These efforts gave rise to the satellite-based augmentation system (SBAS) concept which is to isolate individual error source for navigation satellites based on a network of reference stations, and then 
broadcast the corrections and integrity messages by geostationary satellites over its service area [1]. Although the SBAS system is originally developed for civil aviation use, it could also be used for other applications, such as precision farming, on-road vehicle fleet management, positioning of oil exploration platforms at sea, and so on.

Several countries and regions have developed their own SBAS systems. Currently, there are 4 operational SBAS systems, including the US Wide Area Augmentation System (WAAS), the European Geostationary Navigation Overlay Service (EGNOS), the Indian GPS Aided GEO Augmented Navigation (GAGAN), and the Japanese Multi-functional Satellite Augmentation System (MSAS) (http://mgex.igs.org/IGS_MGEX_Status_SBAS.php). Russia has also deployed its SBAS system, named as the System for Differential Corrections and Monitoring (SDCM). Currently, three SDCM satellites are broadcasting augmentation messages for GPS and GLObal NAvigation Satellite System (GLONASS) over Russia (http:/ / www.sdcm.ru/index_eng.html). In addition, some countries, such as Australia and Nigeria, are testing their SBAS systems (http:/ / mgex.igs.org/IGS_MGEX_Status_SBAS.php). China is also planning to broadcast SBAS messages via BeiDou-3 geostationary satellites [2].

The SBAS systems have been developed in accordance with the common Radio Technical Commission for Aeronautics (RTCA) aviation standard, MOPS 229D (Minimum Operational Performance Standards for Global Positioning System/Wide Area Augmentation System Airborne Equipment version D). The SBAS corrections include satellite orbit correction, satellite clock correction, and ionospheric correction. The satellite orbit and clock corrections consist of long-term and fast correction data. The long-term corrections are intended to correct satellite orbit errors and the slow-varying part of satellite clock errors, while the fast corrections are designed to compensate for rapidly changing part of GPS clock errors. The ionospheric corrections are provided in the form of gridded vertical ionospheric delay. The users can calculate the vertical delay at the ionospheric pierce point (IPP) of the observed satellite through interpolation using vertical delays at nearby predefined ionospheric grid points (IGPs). It should be noted that there is no fixed update rate for specific SBAS correction types. Generally, fast corrections are updated at a high rate, while long-term satellite corrections and ionospheric corrections are updated at a relatively low rate [1].

In recent years, real-time high-precision Global Navigation Satellite System (GNSS) positioning has been attracting more and more attention in the GNSS community. The SBAS correction messages are transmitted in real time through SBAS satellites. Unlike the International GNSS Service (IGS) real-time service (RTS) [3,4], which requires users to access the internet, the SBAS message transmission does not require extra data links. Therefore, SBAS correction is a good choice or alternate to conduct real-time high-precision GNSS positioning. Some previous studies on precise point positioning (PPP) with WAAS/EGNOS/MSAS corrections showed that the SBAS-based PPP solution can achieve static positioning accuracy of several decimeters and kinematic positioning accuracy at sub-meter level [5,6]. The WAAS/EGNOS/MSAS ionospheric corrections were used by Kim and Lee for orbit determination of low earth orbiting satellites during the high geomagnetic activity period of 2012 [7]. The GAGAN corrections were applied to Single Point Positioning (SPP) by Pungpet et al. and the evaluation in Thailand from 1 January 2017 to 31 March 2017 showed that no significant improvements were gained due to the fact that GAGAN's ionosphere correction is not suitable for Thailand [8]. Similar research on the performance of GAGAN over Sri Lanka was conducted by Dammalage et al [9]. The performance comparison of EGNOS and SDCM in different user scenarios in Finland were carried out in 2016 [10]. In addition, the maritime application of EGNOS was explored by Lopez and Anton [11]. Except for using only SBAS corrections for positioning, the open-source PPP client of the Centre National d'Etudes Spatiales (CNES) PPP-WIZARD provides a PPP processing strategy by mixed use of SBAS ionospheric corrections and RTS precise ephemeris products [12]. As for the accuracy of SBAS corrections, Rovira-Garcia et al. assessed the ionospheric correction accuracy of WAAS and EGNOS, which indicates that the ionospheric corrections from these two SBAS systems can eliminate about $85 \%$ of the total slant ionospheric delay [13]. Bahrami et al. evaluated the accuracy of the WAAS and EGNOS orbit and clock corrections and showed that the scatter of SBAS-corrected 
GPS broadcast orbit and clock errors exceeds that of the GPS-only broadcast orbit and clock errors for GPS Block IIR, IIR-M and IIF satellites [14]. However, to date, there no comprehensive accuracy evaluation of corrections of different SBAS systems including WAAS, EGNOS, MSAS, GAGAN, and SDCM. Given the increasing application of SBAS systems, such a comprehensive evaluation is of great interest to the GNSS community.

In this contribution, we carry out a comprehensive accuracy evaluation and comparison of the orbit, clock and ionospheric corrections from five currently available SBAS L1 services. The rest of the paper is organized as follows. The methodologies to evaluate SBAS orbit, clock and ionospheric corrections are first presented in detail in the next section. Then the accuracies of the orbit, clock and ionospheric corrections from the five SBAS systems over a period of half a year (from 1 January 2018, to 30 June 2018) are evaluated using IGS final ephemeris products and ionospheric delays derived from code-leveled phase ionosphere measurements as the references. Meanwhile, GPS broadcast orbit, clock and ionospheric correction are also evaluated at the same time for comparison. The results and findings are discussed in Section 4 , and conclusions are drawn in the last section.

\section{Methodology}

\subsection{Satellite-Based Augmentation System (SBAS) Orbit and Clock Correction Evaluation Method}

IGS final products exhibit an orbit and clock accuracy at 2.5 centimeters and 75 picoseconds level (http: / / www.igs.org/products). Therefore, the precise products can be used as the reference to evaluate SBAS orbit and clock corrections. In this section, the methods to calculate the orbit and clock with SBAS corrections are presented first, then the method for assessing the accuracy of SBAS-derived orbits and clocks with respect to IGS final products is discussed.

\subsubsection{Orbit and Clock Calculation with SBAS Corrections}

As previously mentioned, the SBASs provide long-term and fast corrections for satellite orbit and clock. The long-term correction message contains components to correct the satellite position, velocity, clock offset, and clock drift. The position and clock offset components are always broadcasted while the velocity and clock drift components are not always included in the message. There is an indicator in the message to show whether the velocity and clock drift components are available or not. When the velocity code in the message is not set, velocity and clock drift should be treated as zero. As for fast corrections, they are designed to correct the rapidly changing part of satellite clock errors and broadcast in the form of pseudo-range correction (PRC) [1].

The corrected satellite position $r(t)$ at time $t$ can be computed as

$$
\boldsymbol{r}(t)=\boldsymbol{r}_{\text {broadcast }}(t)+\left[\begin{array}{c}
\delta x \\
\delta y \\
\delta z
\end{array}\right]+\left[\begin{array}{c}
\delta \dot{x} \\
\delta \dot{y} \\
\delta \dot{z}
\end{array}\right] \cdot\left(t-t_{0}\right)
$$

where $\boldsymbol{r}_{\text {broadcast }}(t)$ is the satellite position vector computed using the broadcast ephemeris, $\left[\begin{array}{lll}\delta x & \delta y & \delta z\end{array}\right]^{T}$ and $\left[\begin{array}{ccc}\delta \dot{x} & \delta \dot{y} & \delta \dot{z}\end{array}\right]^{T}$ denote satellite position and velocity correction vectors, $t_{0}$ is the time of day applicability of the long-term correction. It is noted that the issue of data (IOD) in the broadcast ephemeris and that in the long-term correction message must match with each other.

The correction to the satellite clock using the long-term correction message can be given as:

$$
\delta t_{\text {long }}(t)=\delta a_{f_{0}}+\delta a_{f_{1}} \cdot\left(t-t_{0}\right)
$$

where $\delta a_{f_{0}}$. and $\delta a_{f_{1}}$ represent satellite offset and drift components in the message. As mentioned above, in addition to the long-term correction message, the fast correction message also contributes to the satellite clock correction, which is given as: 


$$
\delta t_{\text {fast }}(t)=\left(\operatorname{PRC}\left(t_{o f}\right)+R R C\left(t_{o f}\right) \cdot\left(t-t_{0 f}\right)\right) / c
$$

where $c$ and $t_{\text {of }}$ denote velocity of light and time of day applicability of the fast correction, $P R C\left(t_{o f}\right)$ is the broadcast PRC value, and $R R C\left(t_{o f}\right)$ is the range-rate correction (RRC). However, RRC is not included in the fast correction message. It can be computed by differencing the current and previous PRC values as:

$$
\operatorname{RRC}\left(t_{\text {of }}\right)=\left(\operatorname{PRC}\left(t_{o f}\right)-\operatorname{PRC}\left(t_{\text {of,previous }}\right)\right) /\left(t_{\text {of }}-t_{\text {of, previous }}\right)
$$

where $P R C\left(t_{o f}\right.$, previous $)$ is the previous broadcast PRC value at the time of day applicability $t_{o f}$, previous. After applying both long- and fast-term correction, the corrected satellite clock offset $d T(t)$ for L1 C/A signal is given by:

$$
d T(t)=d T_{\text {broadcast }}(t)-T_{G D}+\delta t_{\text {long }}(t)+\delta t_{\text {fast }}(t)
$$

$d T_{\text {broadcast }}(t)$ is the satellite clock offset at the time of $t$ computed with the GPS broadcast navigation data, and $T_{G D}$ is the satellite time group delay provided in the the GPS broadcast navigation data.

\subsubsection{SBAS-Derived Orbit and Clock Error Calculation}

The IGS precise orbit products are used as the references in the assessment of SBAS-derived orbits, therefore adequate care must be taken to ensure the compatibility of different types of orbit. Firstly, SBAS-derived orbits are referred to the antenna phase center (APC), while IGS precise orbit products are provided with respect to the center-of-mass (COM). Evidently, the comparison of these two types of orbits cannot be conducted directly. The IGS antenna information file provides the satellite antenna phase center offset (PCO) vectors in the spacecraft body-fixed frame. The coordinate transformation from COM to APC for IGS precise orbits can be computed with the known PCO vector $d \boldsymbol{r}_{P C O}$ and the modeled spacecraft attitude, which can be given as $[15,16]$

$$
\boldsymbol{r}_{A P C}=\boldsymbol{r}_{C O M}+\boldsymbol{R}_{\text {spacecraft }}^{E C E F} \cdot d \boldsymbol{r}_{P C O}
$$

where $\boldsymbol{r}_{A P C}, \boldsymbol{r}_{C O M}$ are satellite APC and COM Earth-centered Earth-fixed (ECEF) Cartesian coordinate vectors, $\boldsymbol{R}_{\text {spacecraft }}^{E C E F}$ denotes the transformation matrix from the spacecraft body-fixed frame to the ECEF frame. The transformation matrix $\boldsymbol{R}_{\text {spacecraft }}^{E C E F}$ is expressed with the unit vectors of $x, y$ and $z$ axis in the spacecraft body-fixed frame as follow [17]

$$
\boldsymbol{R}_{\text {spacecraft }}^{E C E F}=\left[\begin{array}{lll}
\boldsymbol{e}_{\text {spacecraft }, x} & \boldsymbol{e}_{\text {spacecraft,y }} & \boldsymbol{e}_{\text {spacecraft }, z}
\end{array}\right]
$$

where

$$
\left\{\begin{array}{c}
\boldsymbol{e}_{\text {spacecraft }, z}=-\frac{\boldsymbol{r}_{\text {sat }}}{\left|\boldsymbol{r}_{\text {sat }}\right|} \\
\boldsymbol{e}_{\text {spacecraft }, y}=\boldsymbol{e}_{\text {spacecraft }, z} \times \boldsymbol{e}_{\text {spacecraft }, x}
\end{array}\right.
$$

$\boldsymbol{r}_{\text {sat }}$ is the ECEF Cartesian coordinate vector of satellite, and $|*|$ denotes the norm of the vector. The unit vector of $x$ axis $\boldsymbol{e}_{\text {spacecraft } x}$ can be obtained by rotating the unit vector of the spacecraft velocity around the $z$-axis by yaw angle. The yaw attitude model of GPS Block IIA, IIR and IIF satellites can be referred to [17-19].

In addition, SBAS-derived and IGS precise orbits are formally referred to different reference frames. The current IGS precise orbits are referred to IGS14, which is aligned with the latest International Terrestrial Reference Frame (ITRF) called ITRF2014 [20]. WAAS adopts WGS84 as the coordinate reference system to broadcast satellite orbit corrections [21], and the most recent WGS84 realization (G1762) agrees with ITRF2008 at the centimeter level [22]. As presented in the International Terrestrial Reference Service (ITRS) website (http:/ /itrf.ensg.ign.fr/trans_para.php), the differences between 
ITRF2008 and ITRF2014 are at the millimeter-level. EGNOS reference frame, named EGNOS Terrestrial Reference Frame (ETRF), is periodically aligned on ITRF within a consistency of a few centimeters [23]. We cannot find any official documentation or information about the reference frames adopted for the MSAS, GAGAN, and SDCM. However, an alignment to WGS84 can be expected since the requirements of international air navigation must be fulfilled [5]. Therefore, the differences between reference frames mentioned above would not exceed a few centimeters, which can be neglected in the accuracy assessment of SBAS-derived orbits.

Usually, the orbit errors are presented in the satellite along-track, cross-track, and radial directions. The transformation of orbit errors from ECEF to the satellite along-track, cross-track and radial frame is given by $[24,25]$ :

$$
\left[\begin{array}{c}
\Delta r_{\text {along }} \\
\Delta r_{\text {cross }} \\
\Delta r_{\text {radial }}
\end{array}\right]=\left[\begin{array}{lll}
\boldsymbol{e}_{\text {along }} & \boldsymbol{e}_{\text {cross }} & \boldsymbol{e}_{\text {radial }}
\end{array}\right] \cdot\left[\begin{array}{c}
\Delta r_{x} \\
\Delta r_{y} \\
\Delta r_{z}
\end{array}\right]
$$

with

$$
\left\{\begin{array}{c}
\boldsymbol{e}_{\text {along }}=\frac{v_{I G S}}{\left|v_{I G S}\right|} \\
\boldsymbol{e}_{\text {cross }}=\frac{\boldsymbol{r}_{I G S} \times \boldsymbol{v}_{I G S}}{\left|\boldsymbol{r}_{I G S} \times \boldsymbol{v}_{I G S}\right|} \\
\boldsymbol{e}_{\text {radial }}=\boldsymbol{e}_{\text {along }} \times \boldsymbol{e}_{\text {cross }}
\end{array}\right.
$$

where $\boldsymbol{r}_{I G S}, \boldsymbol{v}_{I G S}$ are satellite position and velocity vector in the IGS orbital frame. $\Delta r_{x}, \Delta r_{y}$ and $\Delta r_{z}$ are the orbit errors in the $\mathrm{x}-, \mathrm{y}$ - and $z$-axis of IGS orbital frame, which are computed by SBAS-derived orbits minus IGS precise orbits. It is noted that the differences between COM and APC should be removed according to Equation (6).

Similar to orbit comparison, SBAS-derived clocks and IGS precise clock products cannot be compared directly. SBAS-derived clock offsets computed with Equation (5) are referred to C1 (L1 C/A signal) [1]. However, the ionosphere-free combination of P1 (L1 P signal) and P2 (L2 P signal) observations are employed in the generation of IGS precise clock products [26,27]. A corresponding correction should be applied to eliminate the inconsistency between signal combinations adopted by SBAS-derived clocks and IGS precise clock products. The hardware delay difference between C1 and $\mathrm{P} 1 / \mathrm{P} 2$ ionosphere-free combination can be given as [28,29]:

$$
\begin{aligned}
B_{C 1}-B_{P 1 / P 2} & =B_{C 1}-\left(\frac{f_{1}{ }^{2}}{f_{1}^{2}-f_{2}{ }^{2}} B_{P 1}-\frac{f_{2}{ }^{2}}{f_{1}{ }^{2}-f_{2}{ }^{2}} B_{P 2}\right) \\
& =\left(B_{C 1}-B_{P 1}\right)-\frac{f_{2}{ }^{2}}{f_{1}^{2}-f_{2}{ }^{2}}\left(B_{P 1}-B_{P 2}\right) \\
& =D C B_{P 1-C 1}+\frac{f_{2}{ }^{2}}{f_{1}{ }^{2}-f_{2}{ }^{2}} D C B_{P 1-P 2}
\end{aligned}
$$

where $B_{C 1}, B_{P 1}$ and $B_{P 2}$ are the hardware delays of $C 1, P 1$ and $P 2$ respectively, $B_{P 1 / P 2}$ represents the hardware delay of P1, P2 ionosphere-free combination, $f_{1}, f_{2}$ are the frequency values of L1 and $\mathrm{L} 2, D C B_{P 1-C 1}$ denotes differential code bias between $\mathrm{P} 1$ and $\mathrm{C} 1$, and $D C B_{P 1-P 2}$ represents differential code bias between $P 1$ and $P 2$. The monthly mean values of $D C B_{P 1-C 1}$ and $D C B_{P 1-P 2}$ can be obtained from the Center of Orbit Determination in Europe (CODE) analysis center (ftp://ftp.aiub.unibe.ch/CODE/). Correspondingly, the relationship between two clock offsets referred to $\mathrm{C} 1$ and $\mathrm{P} 1 / \mathrm{P} 2$ can be expressed as:

$$
d T_{C 1}=d T_{P 1 / P 2}+D C B_{P 1-C 1}+\frac{f_{2}^{2}}{f_{1}^{2}-f_{2}^{2}} D C B_{P 1-P 2}
$$

Theoretically, the last term on the right side should be equal to $-T_{G D}$ in Equation (5) [29]. Therefore, the last term in Equation (12) and the term of $-T_{G D}$ in Equation (5) can be omitted in the clock comparisons. In addition, there exist differences in the underlying realization of the SBAS and IGS precise clock time scales. These differences, known as time reference offsets, affect all satellites of a constellation with the same value and vary from one epoch to another. To remove the time reference 
offsets, the average SBAS-minus-IGS clock differences of satellites in a constellation is computed at each epoch, and then the computed average is subtracted from all individual SBAS-minus-IGS clock differences [30].

\subsubsection{Signal-in-Space Range Error (SISRE) Calculation}

The impact of orbit errors on the Signal-in-Space Range Errors (SISREs) relates to the orientation of the line-of-sight. Except for orbit errors, satellite clock offset errors $(\Delta \mathrm{d} T)$ also account for a dominant portion of the signal-in-space errors. The global average SISRE is usually introduced to represent the root mean square (RMS) of SISREs across the portion of the globe view of the satellite. If there is no special explanation, SISRE refers to global average SISRE in this contribution. The combined orbit and clock SISRE can be computed as [30-33]:

$$
\text { SISRE }=\sqrt{\operatorname{rms}\left(w_{\text {radial }} \Delta r_{\text {radial }}-\mathrm{c} \Delta \mathrm{d} T\right)^{2}+w_{\text {along }}^{2} \cdot A^{2}+w_{\text {cross }}^{2} \cdot C^{2}}
$$

where $\operatorname{rms}(*)$ denotes an RMS operation, $A, C$ are the RMSs of the orbit errors in the along-track $\left(\Delta r_{\text {along }}\right)$ and cross-track $\left(\Delta r_{\text {cross }}\right)$ directions, $w_{\text {radial }}=0.98$ and $w_{\text {along }}=w_{\text {cross }}=0.141$ represent the corresponding weight factors, which have been discussed in the literature [31-33]. It should be noted that, for the observer on the surface of the earth, the radial orbit error results in a positive range error, while the clock offset error leads to a negative range error. That is to say, only the difference of the radial orbit error and the clock offset error contributes to the SISRE.

\subsection{Ionospheric Correction Evaluation Method}

In this section, firstly, the method to calculate SBAS ionospheric correction is presented. Secondly, the comparison method between SBAS ionospheric correction and the reference derived from dual-frequency GNSS measurements is discussed.

\subsubsection{SBAS Ionospheric Correction Calculation}

According to RTCA DO-229D, the SBAS ionospheric correction message provides ionospheric vertical delays for specified IGPs at an altitude of $350 \mathrm{~km}$. In order to facilitate flexibility in the location of IGPs, a fixed definition of IGP locations is used. The predefined IGPs are divided into in 11 bands (numbered 0 to 10), Bands 0-8 are vertical bands, and Bands 9-10 are horizontal bands. The distribution of all predefined IGPs are shown in Figure 1. It should be noted that part of IGPs in Bands 9 and 10 are at the same location as IGPs in Bands 0 to 8 . Each SBAS system only broadcast part of the bands to cover its service area and, even for the broadcasted bands, a mask is broadcast to define the IGP locations for providing the most efficient model of the ionosphere [1].

The vertical delays at IGPs are used to interpolate the vertical delay at the IPP of the observed satellite. The position of IPP is defined as the intersection of the ionospheric layer at an altitude of $350 \mathrm{~km}$ and a straight line from the user's location to the satellite. Usually, four IGPs defining a cell or three IGPs defining a triangle that surrounds the IPP are selected to carry out the interpolation according to the IGP mask information. The detailed selection process can further refer to [1]. If any of the selected IGPs is identified as "Do Not Use", there is no ionospheric correction available. Four IGPs around the IPP are preferentially selected to compute the ionospheric delay at IPP. However, if one of the four is identified as "Not Monitored", then the remaining three corrections are used if the IPP is within the triangular region defined by three IGPs. If there are less than three IGPs identified as "Monitored", the ionospheric correction is also not available. It is noted that four selected IGPs must be identified as "Monitored" for the IPP south of $75^{\circ} \mathrm{S}$ or north of $75^{\circ} \mathrm{N}$. 




Figure 1. The predefined global ionospheric grid point (IGP) grids.

For the four-point interpolation, denoting the vertical delay at four IGPs as $V I C_{i}(i=1,2,3,4)$, the interpolated vertical IPP delay VIC can be expressed as a function of IPP latitude $\varphi_{I P P}$ and longitude $\lambda_{I P P}$ :

$$
V I C_{I P P}\left(\varphi_{I P P}, \lambda_{I P P}\right)=\sum_{i=1}^{4} W_{i}\left(x_{I P P}, y_{I P P}\right) V I C_{i}
$$

with

$$
\left\{\begin{array}{l}
W_{1}\left(x_{I P P}, y_{I P P}\right)=x_{I P P} y_{I P P} \\
W_{2}\left(x_{I P P}, y_{I P P}\right)=\left(1-x_{I P P}\right) y_{I P P} \\
W_{3}\left(x_{I P P}, y_{I P P}\right)=\left(1-x_{I P P}\right)\left(1-y_{I P P}\right) \\
W_{4}\left(x_{I P P}, y_{I P P}\right)=x_{I P P}\left(1-y_{I P P}\right)
\end{array}\right.
$$

For IPPs between $85^{\circ} \mathrm{N}$ and $85^{\circ} \mathrm{S}$,

$$
\left\{\begin{array}{l}
x_{I P P}=\frac{\lambda_{I P P}-\lambda_{1}}{\lambda_{2}-\lambda_{1}} \\
y_{I P P}=\frac{\varphi_{I P P}-\varphi_{1}}{\varphi_{2}-\varphi_{1}}
\end{array}\right.
$$

where $\lambda_{1}$ denotes the longitude of IGPs west of IPP, $\lambda_{2}$ is the longitude of IGPs east of IPP, $\varphi_{1}$ represents the latitude of IGPs south of IPP, $\varphi_{2}$ is the latitude of IGPs north of IPP. Note that if $\lambda_{1}$ and $\lambda_{2}$ cross $180^{\circ}$ of longitude, the calculation of $x_{I P P}$ should account for the discontinuity in longitude. For IPPs north to $85^{\circ} \mathrm{N}$ or south to $85^{\circ} \mathrm{S}$,

$$
\left\{\begin{array}{l}
y_{I P P}=\frac{\left|\varphi_{I P P}\right|-85^{\circ}}{10^{\circ}} \\
x_{I P P}=\frac{\lambda_{I P P}-\lambda_{3}}{90^{\circ}} \cdot\left(1-2 y_{I P P}\right)+y_{I P P}
\end{array}\right.
$$

$\lambda_{3}$ is longitude of the closest IGP to the west of the IPP.

For the three-point interpolation between $75^{\circ} \mathrm{S}$ and $75^{\circ} \mathrm{N}$, a similar mathematical formulation can be used:

$$
V I C_{I P P}\left(\varphi_{I P P}, \lambda_{I P P}\right)=\sum_{i=1}^{3} W_{i}\left(x_{I P P}, y_{I P P}\right) V I C_{i}
$$


with

$$
\left\{\begin{array}{c}
W_{1}\left(x_{I P P}, y_{I P P}\right)=y_{I P P} \\
W_{2}\left(x_{I P P}, y_{I P P}\right)=1-x_{I P P}-y_{I P P} \\
W_{3}\left(x_{I P P}, y_{I P P}\right)=y_{I P P}
\end{array}\right.
$$

where the determination of $x_{I P P}$ and $y_{I P P}$ is the same as Equation (16).

The slant ionospheric correction can be computed with vertical delay divided by the mapping function

$$
S I C=\frac{V I C}{\sqrt{1-\left(\frac{R_{e} \cos E}{R_{e}+h_{I}}\right)^{2}}}
$$

where $E$ is the elevation angle of the satellite with respect to the user's location, $R_{e}$ is the approximate spherical earth radius and it is taken to be $6378.1363 \mathrm{~km}, h_{I}$ represents the height of the ionospheric layer, which is $350 \mathrm{~km}$ as mentioned above [1].

\subsubsection{Ionospheric Correction Error Calculation}

The ionosphere measurements for code and phase can be written as [34,35]:

$$
\left\{\begin{array}{c}
P I=P_{1}-P_{2}=\gamma \cdot I_{1}+c \cdot D C B_{r, P_{1}-P_{2}}+c \cdot D C B_{P_{1}-P_{2}}^{s} \\
L I=L_{1}-L_{2}=-\gamma \cdot I_{1}+\lambda_{1} N_{1}-\lambda_{2} N_{2}
\end{array}\right.
$$

where $P_{i}$ and $>L_{i}$ are the raw code and phase observations at the $i^{\text {th }}$ frequency, $I_{1}$ denote the slant ionospheric delay at the first frequency, $\gamma=1-f_{1}^{2} / f_{2}^{2}$ is the scale factor and $f_{i}$ denote the $i^{\text {th }}$ frequency value, $c$ represents the speed of light, $D C B_{r, P_{1}-P_{2}}$ and $D C B_{P_{1}-P_{2}}^{s}$ are the differential code biases (DCBs) at the receiver and satellite, $\lambda_{i}$ denotes the wavelength of the $i^{\text {th }}$ frequency and $N_{i}$ represents the corresponding phase ambiguity which has absorbed phase bias $(i=1,2)$. Generally, the precision of phase ionosphere measurement is much higher (approximately 2 orders of magnitude) than that of code ionosphere measurement; however, there is an unknown ambiguity in the phase ionosphere measurement. On contrast, the code ionosphere measurement has significantly larger noise and multipath, but it can provide an absolute value of the ionospheric delay after correcting the satellite and receiver DCBs. The ionospheric delays can be extracted from phase ionosphere measurement by adjusting its level based on code ionosphere measurement. This technique to extract ionospheric delay is called "levelling carrier phase to code" and is widely adopted by IGS analysis centers for global ionosphere map modeling, e.g., JPL [36], WHU [37], CAS [38]. The code-leveled phase ionosphere measurement can be written as [36,39,40]:

$$
\overline{L I}\left(t_{i}\right)=\frac{\sum_{i=1}^{n}\left(P I\left(t_{i}\right)+L I\left(t_{i}\right)\right)}{n}-L I\left(t_{i}\right)=\gamma \cdot I_{1}\left(t_{i}\right)+c \cdot D C B_{r, P_{1}-P_{2}}+c \cdot D C B_{P_{1}-P_{2}}^{s}
$$

$L I\left(t_{i}\right), P I\left(t_{i}\right)$ are the phase and code ionosphere combinations at the epoch time $t_{i}(i=1, \cdots, n)$, and $n$ is the number of epochs in the continuous arc where all phase measurements of this satellite share a common phase ambiguity. Accordingly, the slant ionospheric delay derived from code-leveled phase ionosphere measurement is given by:

$$
I_{1}\left(t_{i}\right)=\left(\overline{L I}\left(t_{i}\right)-c \cdot D C B_{r, P_{1}-P_{2}}-c \cdot D C B_{P_{1}-P_{2}}^{s}\right) / \gamma
$$

When there are no P1 observations, $\mathrm{C} 1$ observations can be used instead. The satellite and receiver DCBs are obtained from the ionosphere products or monthly DCB products provided by the Center for Orbit Determination in Europe (CODE). In this paper, we use slant ionospheric delays derived from code-leveled phase ionosphere measurements as the references to evaluate the SBAS ionospheric corrections. 


\section{Experiment and Results}

To assess the accuracy of SBAS orbit, clock and ionospheric corrections, the SBAS message files, from 1 January 2018 to 30 June 2018, are downloaded from the CNES Navigation and Time Monitoring Facility (NTMF) FTP server (ftp:/ / serenad-public.cnes.fr/SERENAD0/FROM_NTMFV2/MSG/). For each SBAS system, only SBAS message files from two satellites are collected. These files are provided in the receiver independent exchange (RINEX) 2.12 type B format [41]. The SBAS satellites broadcast one message per second and thus the number of SBAS messages during the entire assessment period is expected to be $15,638,400$. The missing number of SBAS messages for each satellite is counted and given in Table 1 . The availability of SBAS messages varies from different SBAS satellites. The availability of PRNs 135, 138, 120, 123, 129, 137, and 127 are close to $100 \%$. However, PRNs 128 , 125 and 140 have relatively lower availability, especially PRN 125, of which the availability is $85.9 \%$. Afterward, two sets of experiments are conducted to evaluate SBAS corrections from five different systems. Firstly, the SBAS orbit and clock corrections are evaluated with IGS final orbit and clock products as the references; Secondly, the SBAS ionospheric corrections are evaluated by comparison to the references derived from dual-frequency GNSS measurements.

Table 1. The number of missing epochs for each satellite-based augmentation system (SBAS) satellite.

\begin{tabular}{ccccccccccc}
\hline System & \multicolumn{1}{c}{ WAAS } & \multicolumn{2}{c}{ EGNOS } & \multicolumn{2}{c}{ MSAS } & \multicolumn{2}{c}{ GAGAN } & \multicolumn{2}{c}{ SDCM } \\
\hline PRN & 135 & 138 & 120 & 123 & 129 & 137 & 127 & 128 & 125 & 140 \\
\hline Number of missing epochs & 3 & 0 & 187 & 171 & 11,284 & 1361 & 9853 & 626,877 & $2,212,623$ & 880,653 \\
\hline
\end{tabular}

\subsection{Evaluation Results of SBAS Orbit and Clock Corrections}

As the references, the IGS final orbit and clock products during the entire evaluation period are downloaded and the orbits are interpolated to the time epochs of IGS clock products with the interval of 30 seconds. The Lagrange interpolation with the polynomial degree of 8 is adopted. The accuracy of IGS precise orbits after interpolation is at $\mathrm{cm}$ level, which is accurate enough for reference [42]. On the other hand, the SBAS-derived orbits and clocks are also calculated at the same time epochs by using SBAS messages and GPS broadcast navigation data. The orbit differences, caused by the situation that SBAS-derived orbits are originally referred to APC and IGS precise orbits are referred to the satellite COM, are corrected according to Equation (6). Similarly, the clock differences due to the inconsistency between C1 signal and P1/P2 ionosphere-free combination adopted by SBAS clock corrections and IGS final clock products respectively, as well as the different underlying realization of the SBAS and IGS precise clock time scales, are also removed by using the method mentioned in Section 2.1.2. Afterward, the orbit and clock errors are calculated by SBAS-derived orbits/clocks minus IGS precise orbits/clocks, the orbit errors are then represented in satellite along-track, cross-track and radial frame based on Equation (9). In addition, the orbit and clock errors of GPS broadcast navigation data have also been calculated at the same time epochs during the evaluation period according to the calculation procedure described in [30].

Figures 2-11 show the probability distributions of satellite orbit errors in the directions of along-track, cross-track, radial and clock errors for SBAS-derived orbits and clocks, which are obtained with orbit and clock corrections from different SBAS satellites. These errors are calculated over the entire evaluation period. Three statistics, including bias, standard deviation (STD) and RMS, are counted and presented in each figure. It should be noted that these three statistics are calculated for each SBAS satellite by using 181-day along-track/cross-track/radial/clock error time series of all available GPS satellites with SBAS corrections. The accuracy of orbit and clock corrections from the same SBAS system only show slight differences, which indicates the consistency of correction messages among SBAS satellites in the same system. When comparing the accuracies of orbit and clock corrections from different SBAS systems, it is found that the SDCM has the best accuracy in terms of along-track, cross-track, radial and clock errors, followed by WAAS and EGNOS, whereas the 
MSAS and GAGAN have worse accuracy. The average RMS of orbit and clock corrections for the two SDCM satellites are $0.871,0.539,0.624$ and $0.689 \mathrm{~m}$ in the along-track direction, cross-track direction, radial direction, and clock error, respectively. Accordingly, the corresponding average RMS values in three orbit directions and clock for WAAS and EGNOS are 1.783, 1.531, 1.341, 1.054 and 2.145, 1.150, $0.774,0.817 \mathrm{~m}$, respectively, whereas the values for MSAS and GAGAN are 4.027, 4.643, 2.894, 2.251 and $2.999,3.215,2.438,2.155 \mathrm{~m}$. Figure 12 shows the probability distributions of orbit errors in the directions of along-track, cross-track, radial as well as clock errors for the GPS broadcast navigation data. The RMS values are $0.942,0.543,0.637$ and $0.702 \mathrm{~m}$ in the along-track, cross-track, radial and clock error respectively. In general, the accuracies of satellite orbits and clocks calculated with current GPS broadcast navigation data are comparable or even better than that of SBAS-derived orbits and clocks, especially for the MSAS- and GAGAN-derived orbits and clocks. The benefits of applying SBAS corrections to GPS broadcast orbits and clocks are marginalized. The results are consistent with the previous literature [14].
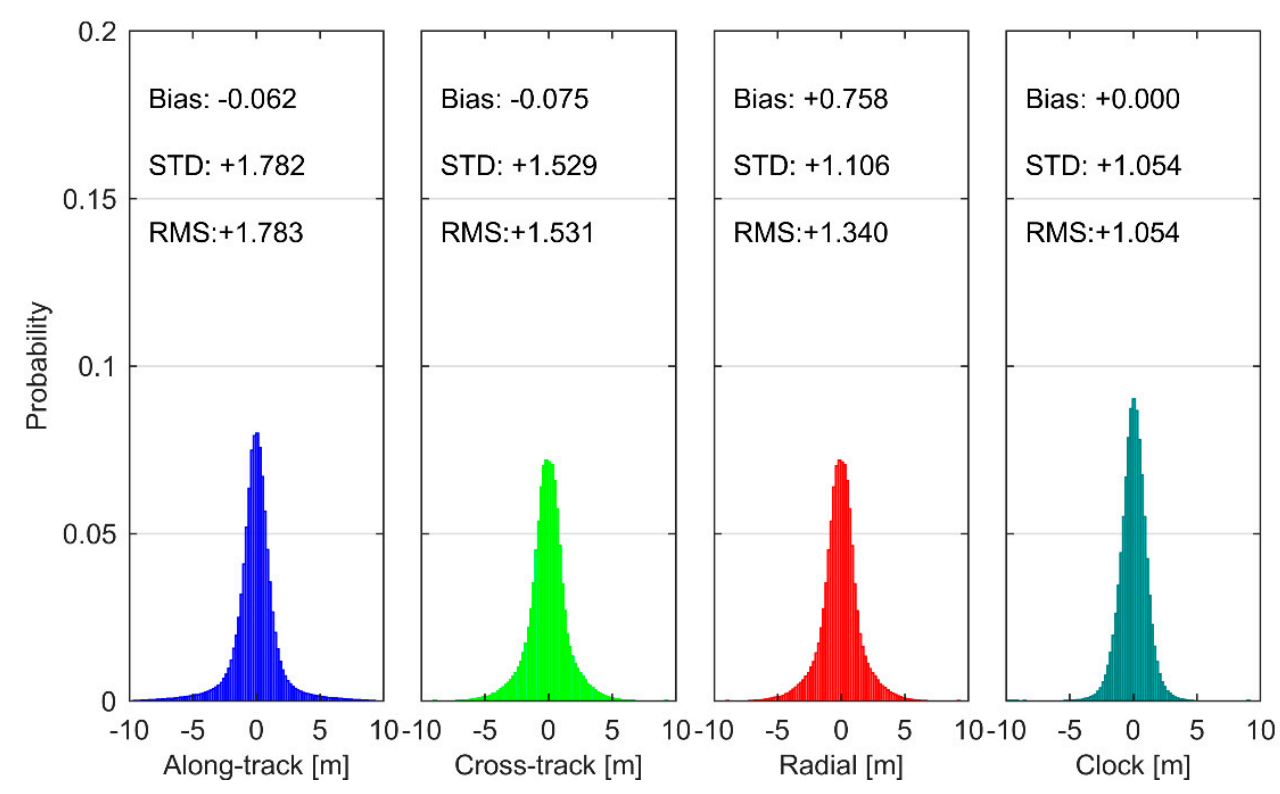

Figure 2. The distribution of SBAS-derived orbit and clock errors for WAAS PRN 135.
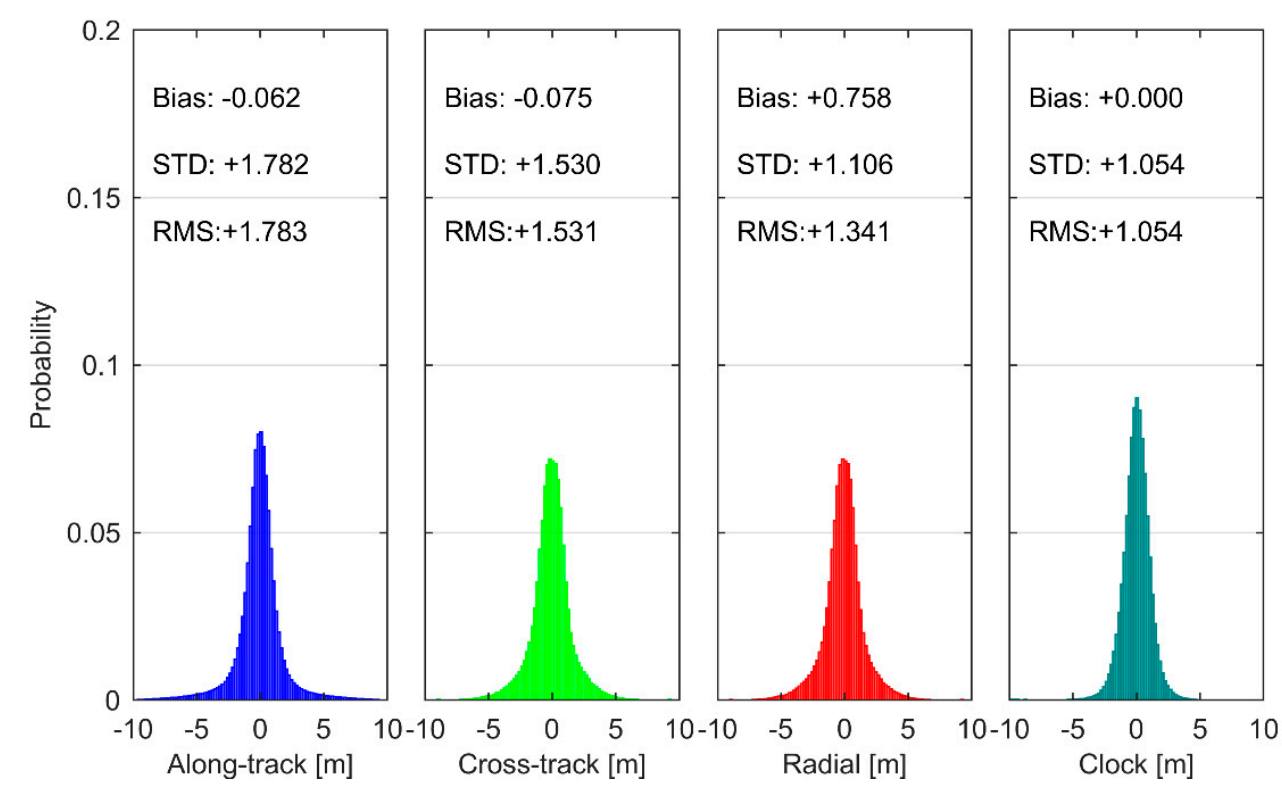

Figure 3. The distribution of SBAS-derived orbit and clock errors for WAAS PRN 138. 


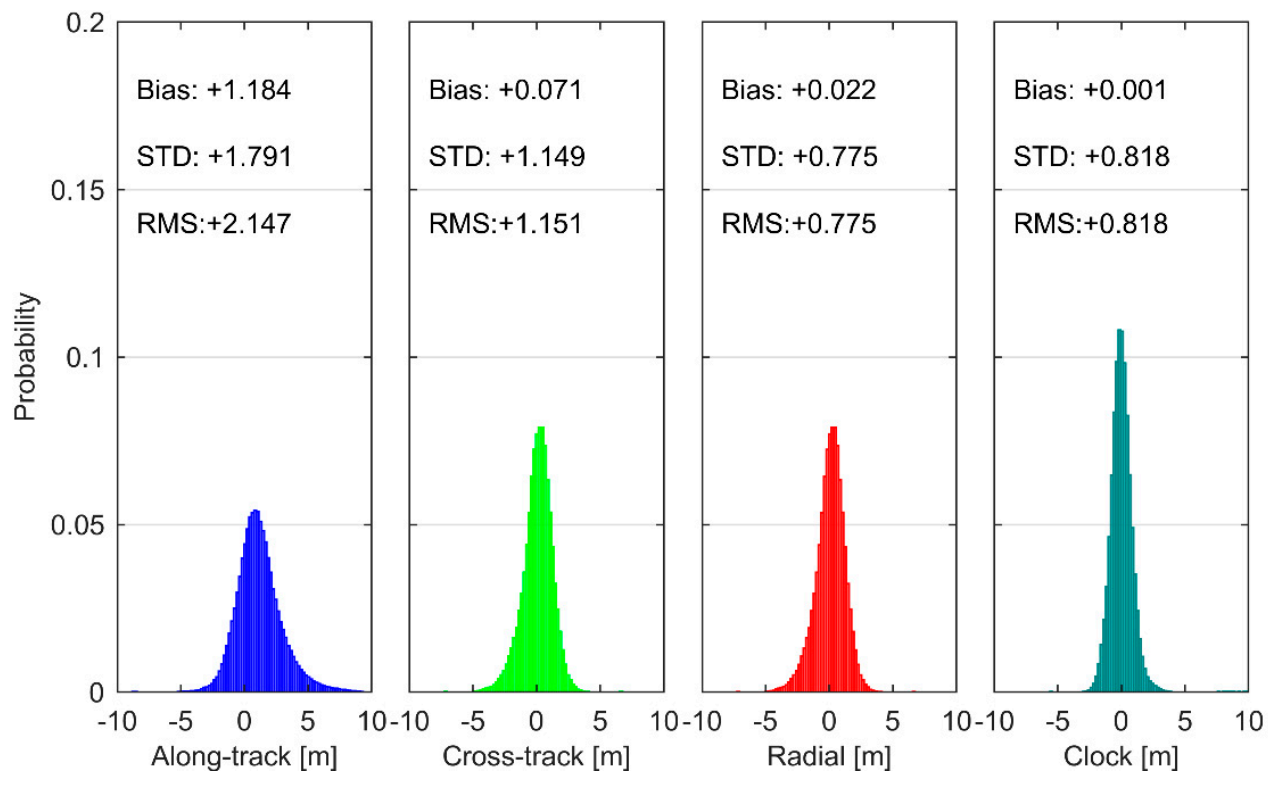

Figure 4. The distribution of SBAS-derived orbit and clock errors for EGNOS PRN 120.
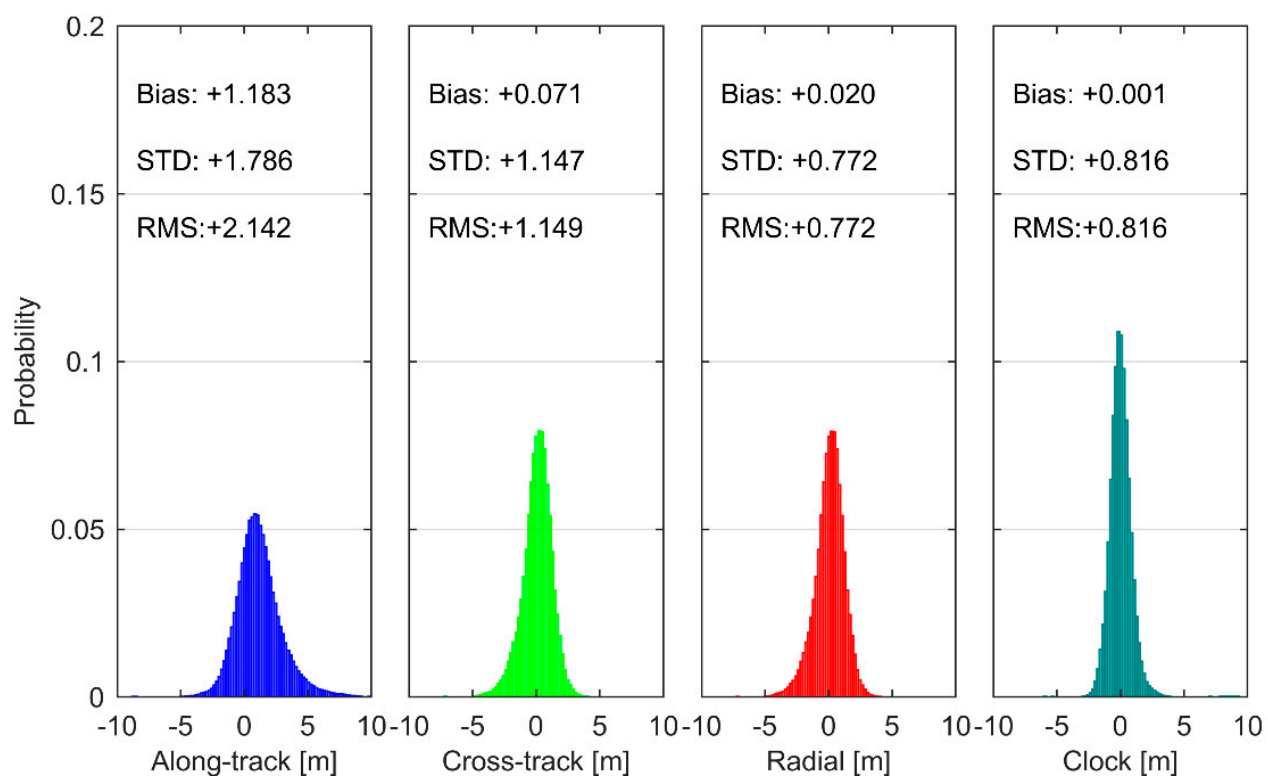

Figure 5. The distribution of SBAS-derived orbit and clock errors for EGNOS PRN 123. 




Figure 6. The distribution of SBAS-derived orbit and clock errors for MSAS PRN 129.
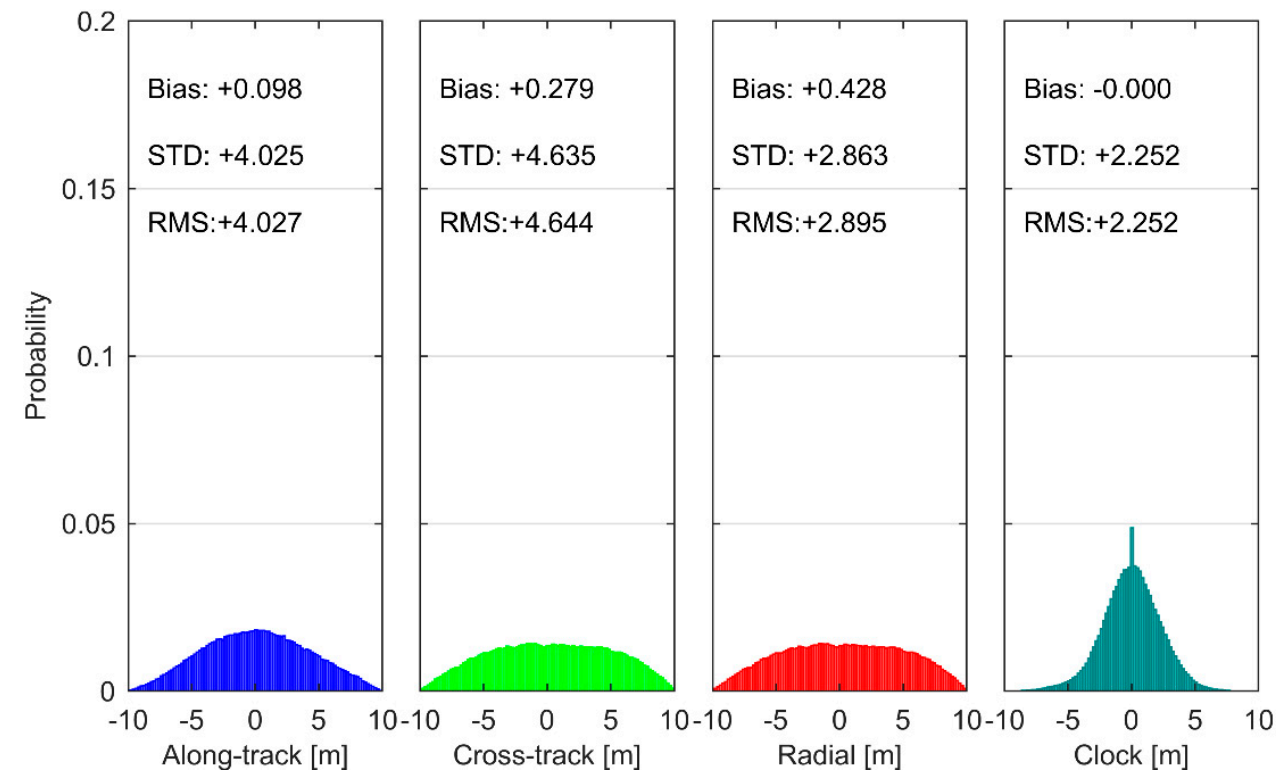

Figure 7. The distribution of SBAS-derived orbit and clock errors for MSAS PRN 137. 


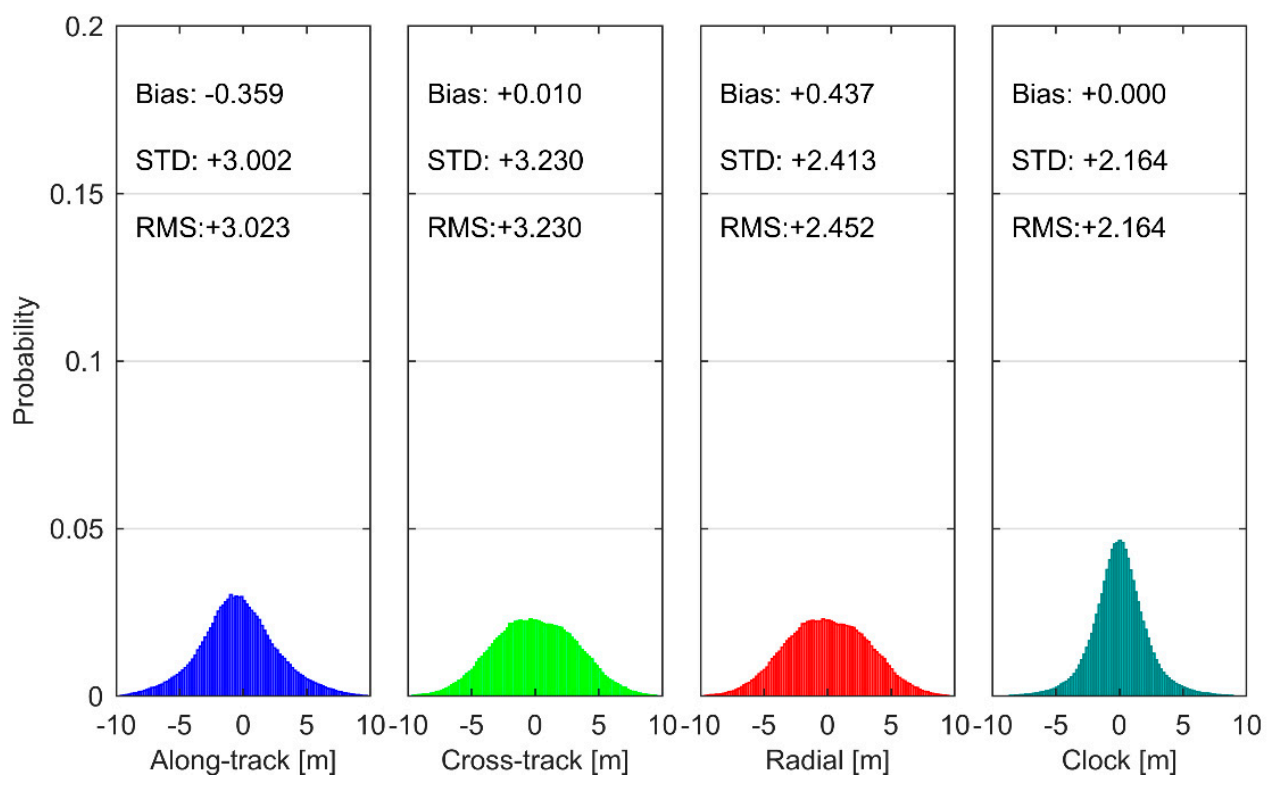

Figure 8. The distribution of SBAS-derived orbit and clock errors for GAGAN PRN 127.


Bias: +0.000

STD: +2.145

RMS:+2.145

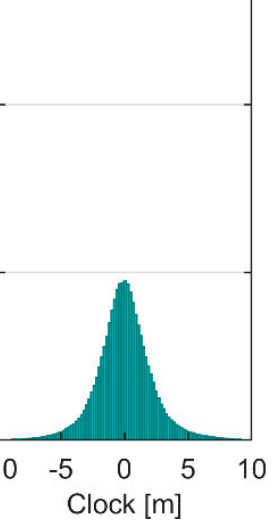

Figure 9. The distribution of SBAS-derived orbit and clock errors for GAGAN PRN 128. 

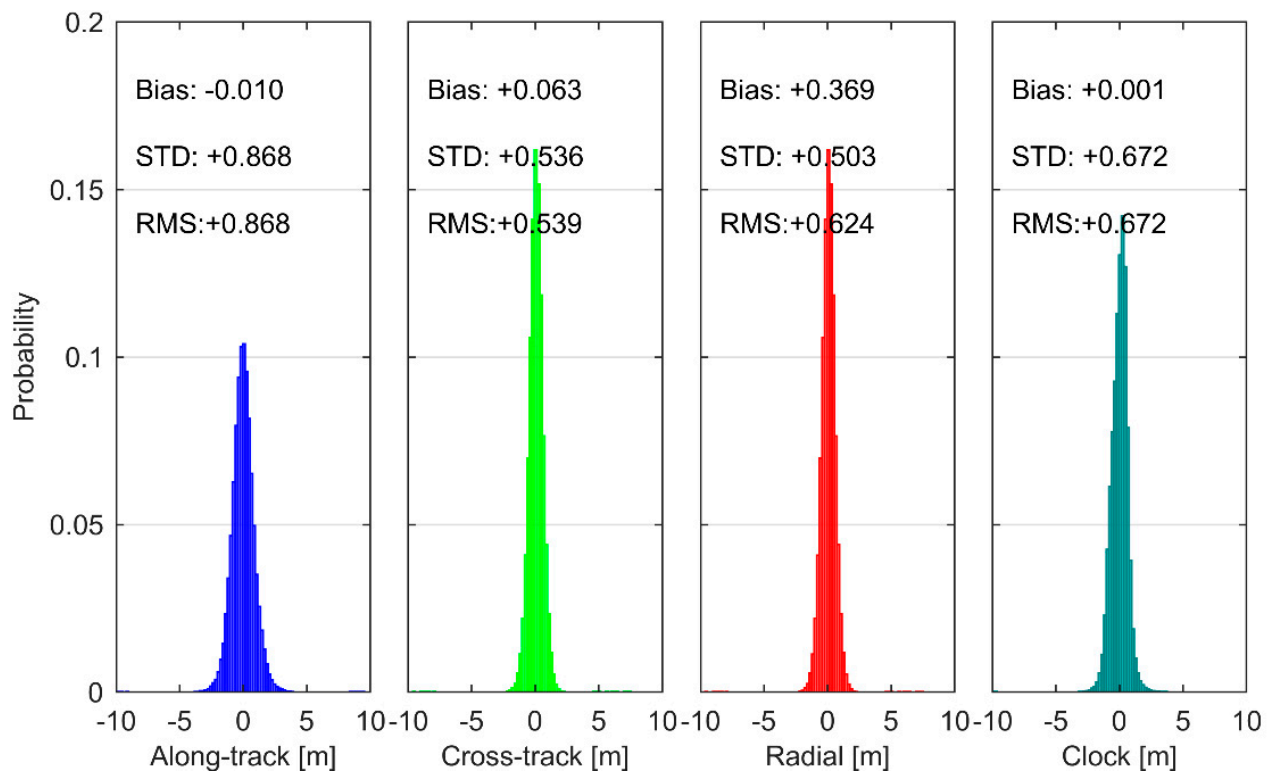

Figure 10. The distribution of SBAS-derived orbit and clock errors for SDCM PRN 125.
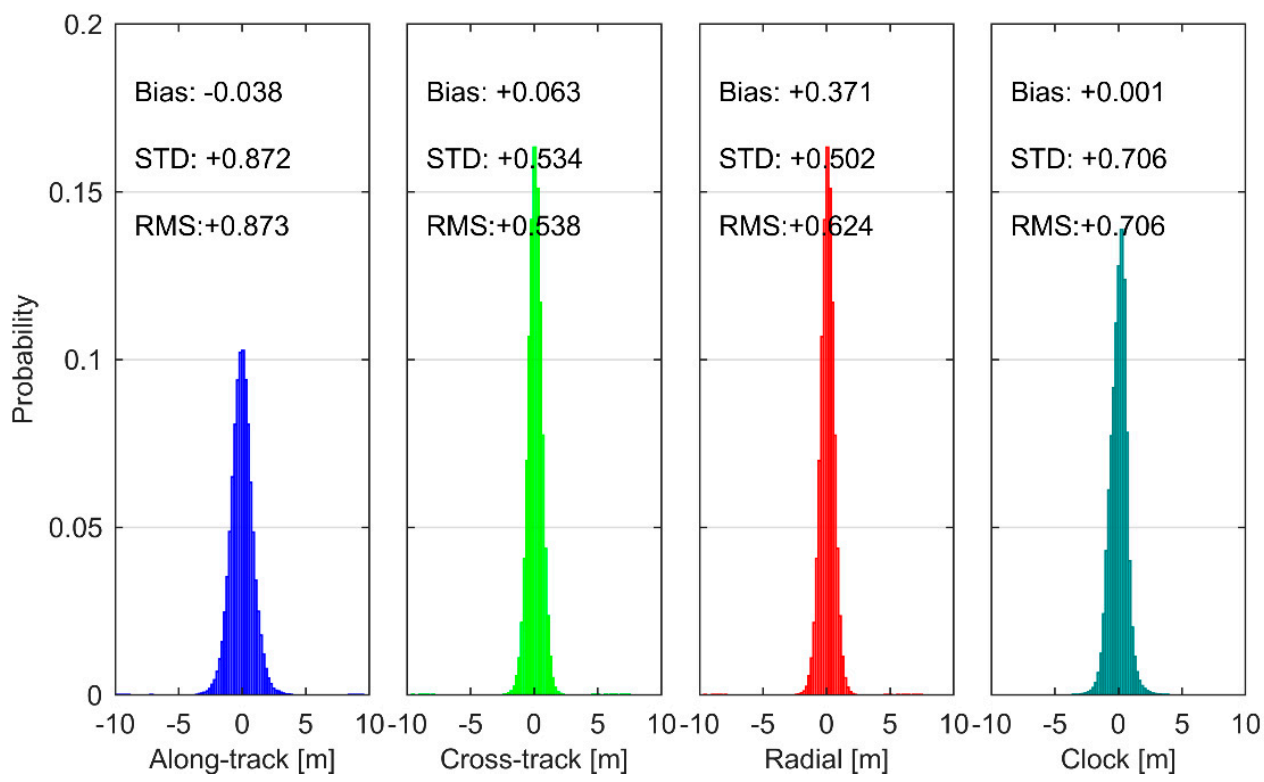

Figure 11. The distribution of SBAS-derived orbit and clock errors for SDCM PRN 140. 

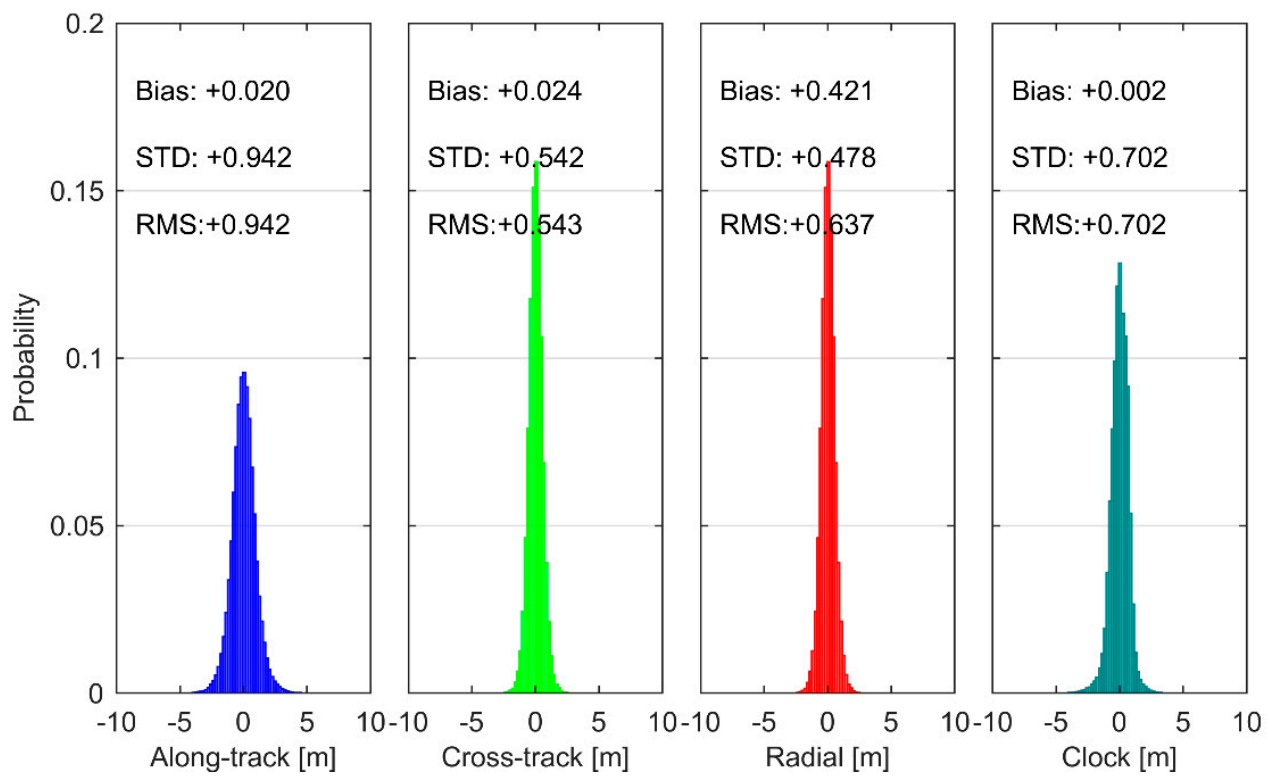

Figure 12. The distribution of orbit and clock errors for Global Positioning System (GPS) broadcast navigation data.

Table 2 presents the SISRE values of SBAS-derived orbits and clocks for each SBAS satellite. SISRE is calculated according to Equation (13) by using 181-day orbit and clock error time series of all available GPS satellites with SBAS corrections. It is observed that the SISRE value is smaller than the addition of the RMS values of radial orbit errors and clock offset errors for each SBAS satellite. This situation should be attributed to the compensation effect of the radial orbit errors and the clock errors when computing the combined orbit and clock SISRE as mentioned above. In addition, orbit and clock corrections provided by the same SBAS system show slight differences in term of SISRE. The SISREs of EGNOS and SDCM systems are significantly smaller than the SISREs of the remaining three SBAS systems, followed by WAAS with the value less than 1 meter. The average SISRE values of MSAS- and GAGAN-derived orbits and clocks are 1.931 and 1.325 meters, respectively. The worse accuracy of MSAS and GAGAN orbit and clock corrections may be attributed to the limited geographic distribution of reference stations [43]. The SISRE of GPS broadcast orbits and clocks is also calculated and given in Table 2. Its value approximates to that of EGNOS- and SDCM-derived orbits and clocks, but significantly smaller than the SISRE values of WAAS-, MSAS- and GAGAN-derived orbits and clocks. The comparison results confirm that the benefits of applying SBAS corrections to GPS broadcast orbits and clocks are marginalized at present in terms of SISRE.

Table 2. The signal-in-space range error (SISRE) values of SBAS-derived and GPS broadcast orbits\& clocks (unit: meters).

\begin{tabular}{cccccccccccc}
\hline Type & \multicolumn{2}{c}{ WAAS } & \multicolumn{2}{c}{ EGNOS } & \multicolumn{2}{c}{ MSAS } & \multicolumn{2}{c}{ GAGAN } & \multicolumn{2}{c}{ SDCM } & GPS Broadcast \\
\hline PRN & 135 & 138 & 120 & 123 & 129 & 137 & 127 & 128 & 125 & 140 & \\
\hline SISRE & 0.954 & 0.954 & 0.646 & 0.645 & 1.931 & 1.931 & 1.336 & 1.313 & 0.634 & 0.666 & 0.695 \\
\hline
\end{tabular}

\subsection{Evaluation Results of SBAS Ionospheric Corrections}

To evaluate the accuracy of the SBAS ionospheric corrections, 27 IGS stations are selected and the geographic distribution of the selected IGS stations is shown in Figure 13. For each SBAS system, 6 IGS stations located in or around service area are selected, except for GAGAN, for which only 3 IGS stations are found. The GNSS raw data with intervals of 30 seconds are downloaded, starting from 1 January to 30 June 2018, from GNSS data and products FTP server of the National Aeronautics and Space Administration (NASA) Crustal Dynamics Data Information System (CDDIS). Only GPS 
measurements are used for deriving the ionospheric delays by using code-leveled phase ionosphere measurements as mentioned in Equation (23). The types of GPS code measurements used in each station are listed in Table 3. To calculate the SBAS ionospheric correction, the ionospheric messages from the SBAS satellite with the highest elevation are used at each station. These ionospheric corrections are calculated at the same time epochs with the downloaded GNSS raw data for each station. The SBAS ionospheric correction errors are calculated with ionospheric delays derived code-leveled phase ionosphere measurements as the references. In addition, ionospheric corrections are obtained with GPS broadcast ionospheric parameters by using the Klobuchar model [44], and GPS broadcast ionospheric correction errors are also calculated with respect to the same references. The evaluation period is near the solar minimum and thus the solar activities are relatively mild (https:/ / www.spaceweatherlive. com/en/solar-activity/solar-cycle). Two standard indices, the disturbance storm time (Dst) and Kp, are used to indicate the geomagnetic activity. Larger Dst index variation and larger Kp index, the intenser the geomagnetic storm. The daily average Dst and $\mathrm{Kp}$ indices during the evaluated period are shown in Figure 14. The Dst indices are all within $\pm 40 \mathrm{nT}$ and the Kp indices are smaller than 5, which indicate the geomagnetic activities are relatively quiet $[45,46]$. In general, it is under relatively mild ionospheric condition during the evaluation period. However, the service areas of WAAS, EGNOS and SDCM are mainly in mid- and high-latitude regions, while the service areas of GAGAN and MSAS are in low- or mid-latitude regions. Considering that the ionospheric condition varies in different latitude regions, it may affect the accuracy of ionospheric corrections from different SBAS systems.

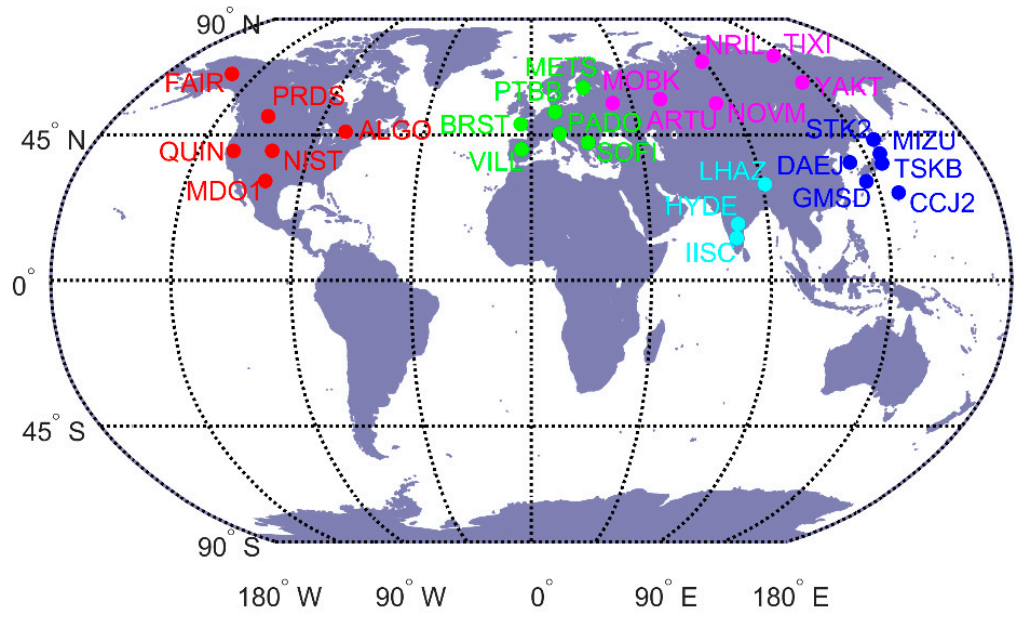

Figure 13. The distribution of the selected IGS stations.

Table 3. The code signals used at each selected IGS station.

\begin{tabular}{|c|c|c|c|c|c|c|c|}
\hline WAAS & $\begin{array}{c}\text { Station } \\
\text { Code signals }\end{array}$ & $\begin{array}{l}\text { ALGO } \\
\mathrm{P} 1+\mathrm{P} 2\end{array}$ & $\begin{array}{c}\text { FAIR } \\
\mathrm{P} 1+\mathrm{P} 2\end{array}$ & $\begin{array}{l}\text { MDO1 } \\
\mathrm{P} 1+\mathrm{P} 2\end{array}$ & $\begin{array}{c}\text { NIST } \\
\mathrm{C} 1+\mathrm{P} 2\end{array}$ & $\begin{array}{l}\text { PRDS } \\
\mathrm{P} 1+\mathrm{P} 2\end{array}$ & $\begin{array}{l}\text { QUIN } \\
\mathrm{P} 1+\mathrm{P} 2\end{array}$ \\
\hline EGNOS & $\begin{array}{c}\text { Station } \\
\text { Code signals }\end{array}$ & $\begin{array}{c}\text { BRST } \\
\mathrm{C} 1 / \mathrm{P} 1+\mathrm{P} 2\end{array}$ & $\begin{array}{l}\text { METS } \\
\mathrm{P} 1+\mathrm{P} 2\end{array}$ & $\begin{array}{l}\text { PADO } \\
\mathrm{P} 1+\mathrm{P} 2\end{array}$ & $\begin{array}{l}\text { PTBB } \\
\mathrm{P} 1+\mathrm{P} 2\end{array}$ & $\begin{array}{c}\text { SOFI } \\
\mathrm{C} 1+\mathrm{P} 2\end{array}$ & $\begin{array}{l}\text { VILL } \\
\text { P1+P2 }\end{array}$ \\
\hline MSAS & $\begin{array}{c}\text { Station } \\
\text { Code signals }\end{array}$ & $\begin{array}{c}\mathrm{CCJ} 2 \\
\mathrm{C} 1+\mathrm{P} 2\end{array}$ & $\begin{array}{c}\text { DAEJ } \\
\mathrm{C} 1+\mathrm{P} 2\end{array}$ & $\begin{array}{l}\text { GMSD } \\
\mathrm{C} 1+\mathrm{P} 2\end{array}$ & $\begin{array}{l}\text { MIZU } \\
\mathrm{P} 1+\mathrm{P} 2\end{array}$ & $\begin{array}{c}\text { STK2 } \\
\mathrm{C} 1+\mathrm{P} 2\end{array}$ & $\begin{array}{r}\text { TSKB } \\
\mathrm{C} 1+\mathrm{P} 2\end{array}$ \\
\hline GAGAN & $\begin{array}{c}\text { Station } \\
\text { Code signals }\end{array}$ & $\begin{array}{l}\text { HYDE } \\
\mathrm{C} 1+\mathrm{P} 2\end{array}$ & $\begin{array}{c}\text { IISC } \\
\mathrm{P} 1+\mathrm{P} 2\end{array}$ & $\begin{array}{l}\text { LHAZ } \\
\mathrm{C} 1+\mathrm{P} 2\end{array}$ & & & \\
\hline SDCM & $\begin{array}{c}\text { Station } \\
\text { Code signals }\end{array}$ & $\begin{array}{l}\text { ARTU } \\
\mathrm{P} 1+\mathrm{P} 2\end{array}$ & $\begin{array}{l}\text { MOBK } \\
\mathrm{P} 1+\mathrm{P} 2\end{array}$ & $\begin{array}{c}\text { NOVM } \\
\text { P1+P2 }\end{array}$ & $\begin{array}{l}\text { NRIL } \\
\text { P1+P2 }\end{array}$ & $\begin{array}{c}\text { TIXI } \\
\text { P1+P2 }\end{array}$ & $\begin{array}{l}\text { YAKT } \\
\mathrm{P} 1+\mathrm{P} 2\end{array}$ \\
\hline
\end{tabular}

${ }^{1}$ For the BRST station, C1\& P2 are used from 1 January 1 to 17 June 2018, and P1 and P2 are used from 18 June to 30 June 2018.

Figure 15 presents the biases and the STDs of SBAS ionospheric correction errors at each selected IGS station. The average biases are $-0.226,-0.106,-0.531,-0.676$ and $0.169 \mathrm{~m}$ over the stations in the WAAS, EGNOS, MSAS, GAGAN and SDCM service area, and the average STDs are $0.438,0.456$, $0.581,0.521$ and $0.490 \mathrm{~m}$, respectively. It is found that the STD values are at similar level, but the bias 
values for the stations located in MSAS and GAGAN service areas are significantly larger than others. The average RMS values of EGNOS, WASS, and SDCM ionospheric corrections are 0.491, 0.505, and $0.523 \mathrm{~m}$, respectively. While MSAS and GAGAN suffer about 3 decimeters worse accuracy with RMS values of 0.795 and $0.858 \mathrm{~m}$, respectively. Therefore, ionospheric corrections provided by EGNOS, WAAS, and SDCM are more accurate than GAGAN and MSAS in term of RMS. Figure 16 shows the bias and the STD values of GPS broadcast ionospheric correction errors at each station. The bias values in all selected station are positive. Most of the bias values are significantly larger than those bias values computed with SBAS ionospheric correction errors at the same station. All STD values are larger than the corresponding STD values calculated with SBAS ionospheric correction errors. The average RMS values over the stations in the WAAS, EGNOS, MSAS, GAGAN and SDCM service areas are 1.482, $1.556,1.626,1.333$ and $1.896 \mathrm{~m}$, respectively. It indicates that the accuracy of GPS ionospheric correction is much worse than SBAS ionospheric correction.

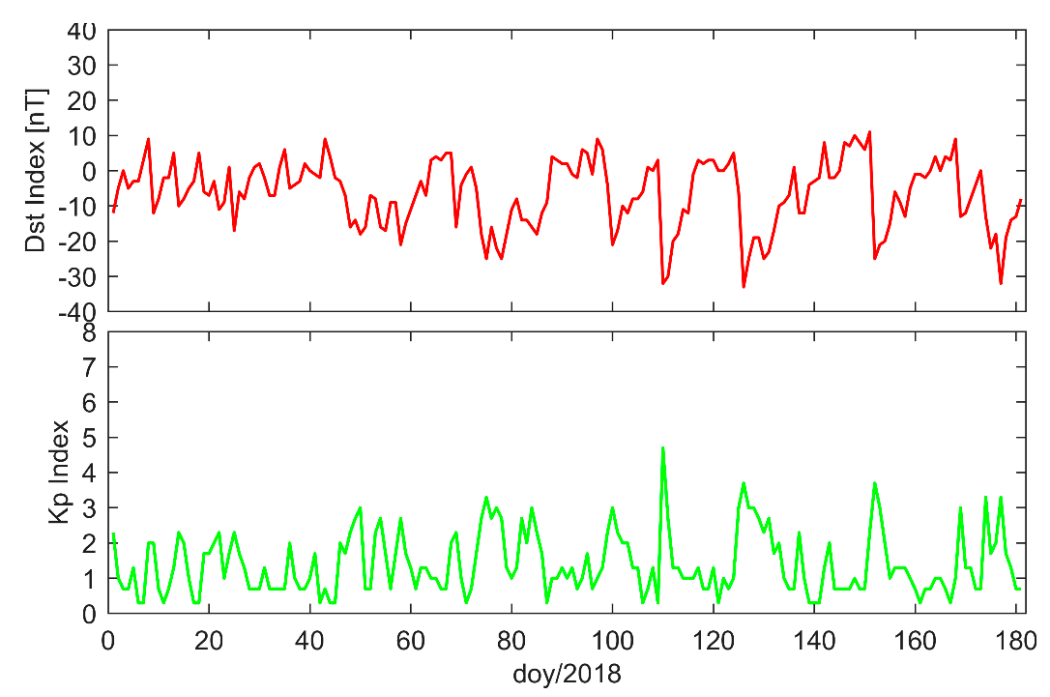

Figure 14. The disturbance storm time (Dst) and Kp indices during the period from 1 January 2018 to 30 June 2018.



Figure 15. The bias and standard deviation (STD) values of SBAS ionospheric correction errors for each selected IGS station. 




Figure 16. The bias and STD values of GPS broadcast ionospheric correction errors for each selected IGS station.

\section{Discussion}

Experimental results show that the accuracy of orbit and clock corrections varies in different SBAS systems. The accuracy of orbit and clock corrections of EGNOS and SDCM systems are significantly better than that of the other three SBAS systems, followed by WAAS, while MSAS and GAGAN provide orbit and clock correction with a relatively worse accuracy. In terms of SBAS ionospheric corrections, the accuracy of ionospheric corrections provided by EGNOS, WAAS, and SDCM are about half a meter, while MSAS and GAGAN suffer from further accuracy degradation of about 3 decimeters. When comparing with GPS broadcast orbit, clock and ionospheric correction, the SISRE degrades with application of SBAS orbit and clock corrections while the accuracy of SBAS ionospheric corrections is still much better than that of GPS broadcast ionospheric corrections.

It should be noted that the SBAS message availability of SDCM PRN 125 is $85.9 \%$, which might affect the assessment slightly. In addition, the service areas of WAAS, EGNOS and SDCM are mainly in mid- and high-latitude regions, while GAGAN and MSAS provide service in low- or mid-latitude regions. To a certain extent, it may affect the accuracy comparision of ionospheric corrections from different SBAS systems. At last, each of the three systems (WAAS, EGNOS and SDCM) has one GEO satellite whose corrections are not included in the evaluation. However, considering that the accuracy of orbit and clock corrections from the same SBAS system only show minor differences, using only two satellites for the assessment of WAAS, EGNOS and SDCM should have only slight impacts on the results.

Several associated aspects which are not discussed in this paper still require further study. Firstly, the assessment under different ionosphere condition needs to be further conducted given that the ionosphere condition during the evaluation period in this paper is relatively mild. Secondly, the consistency between the evaluation results and integrity information broadcasted by different SBAS systems need to be further investigated. Nonetheless, the results of this paper are beneficial for high-precision GNSS positioning using SABS corrections or combining SBAS corrections with other source of corrections. As we know, IGS RTS has been providing openly and freely accessible high-precision correction since 2013. The accuracy of real-time orbit is about $5 \mathrm{~cm}$, and the real-time clock has a standard deviation of 0.1-0.15 ns (http:/ /www.igs.org/rts/monitor). Although there is only one IGS analysis center, CNES, broadcasting RTS ionospheric message, and the SBAS ionospheric 
corrections are still competitive in terms of accuracy [47]. Therefore, it is a good choice to combine RTS multi-GNSS orbit/clock corrections and SBAS ionospheric corrections to conduct real-time multi-GNSS single-frequency PPP.

\section{Conclusions}

The methodologies for assessing the accuracy of SBAS orbit, clock, and ionospheric corrections are presented in this contribution. The orbit and clock references are based on IGS final orbit and clock products. The orbit inconsistency by which SBAS-derived orbits are referred to satellite APC and IGS final precise products are referred to satellite COM are corrected before comparison. The clock inconsistency between SBAS and IGS final clock products caused by different signal combnation and underlying realizationis also removed. The ionospheric reference is obtained with code-leveled phase ionospheric measurement.

Satellite orbit, clock, and ionospheric corrections from five currently available SBAS systems during the period, from 1 January to 30 June 2018, are assessed and analyzed. At the same time, GPS broadcast orbit, clock and ionospheric correction are also evaluated as a comparison. Among the five SBAS systems, the SISRE and ionospheric correction accuracy of EGNOS are 0.645 and $0.491 \mathrm{~m}$, respectively, which outperform other SBASs assessed. The accuracy of SDCM corrections is very similar to that of EGNOS corrections, which is $0.650 \mathrm{~m}$ for the SISRE and $0.523 \mathrm{~m}$ for the ionospheric corrections. The WAAS system provides ionospheric corrections with comparable accuracy of $0.505 \mathrm{~m}$, but SISRE is close to $1 \mathrm{~m}$. However, the accuracies of MSAS and GAGAN corrections are significantly worse than other systems with SISRE of 1.931, $1.325 \mathrm{~m}$ and the ionospheric correction accuracy of 0.795 and $0.858 \mathrm{~m}$. The SISRE of the GPS broadcast orbits and clocks during the evaluation period is $0.695 \mathrm{~m}$, and the accuracies of GPS broadcast ionospheric corrections at the WAAS, EGNOS, MSAS, GAGAN and SDCM service areas are 1.482, 1.556, 1.626, 1.333 and $1.896 \mathrm{~m}$, respectively. It is found that the benefits of applying SBAS corrections to GPS broadcast orbits and clocks are marginalized in terms of SISRE. However, the accuracy of SBAS ionospheric corrections is still much better than that of GPS broadcast ionospheric corrections, which could be useful for single-frequency users.

Author Contributions: Z.N. did literature review, collected data, processed data and prepared the paper draft. P.Z. analyzed the processing results and wrote result part of the paper. F.L. checked the software and validated the processing results. Z.W. and Y.G. contributed to the revision of the paper.

Funding: This study was funded by Key Program of National Natural Science Foundation of China (Grant No.: 41631073), National Natural Science Foundation of China (Grant No.: 41604027) and Qingdao National Laboratory for Marine Science and Technology (Grant No.: QNLM2016ORP0401).

Acknowledgments: The authors acknowledge CNES for providing SBAS RINEX data and IGS for providing observation data.

Conflicts of Interest: The manuscript has not been published elsewhere, and it has not been submitted simultaneously for publication elsewhere. We also have no conflicts of interest to disclose. All authors have seen and approved the manuscript.

\section{References}

1. RTCA. Minimum Operational Performance Standards for Global Positioning System/Wide Area Augmentation System Airborne Equipment, RTCA DO-229D; Radio Technical Commission for Aeronautics (RTCA): Washington, DC, USA, 2006.

2. CSNO. Development of the BeiDou Navigation Satellite System, version 3.0; China Satellite Navigation Office (CSNO): Beijing, China, 2018.

3. Weber, G.; Mervart, L.; Lukes, Z.; Rocken, C.; Dousa, J. Real-time clock and orbit corrections for improved point positioning via NTRIP. In Proceedings of the ION GNSS 2007, Fort Worth, TX, USA, 25-28 September 2007; pp. 1992-1998.

4. Hadas, T.; Bosy, J. IGS RTS precise orbits and clocks verification and quality degradation over time. GPS Solut. 2015, 19, 93-105. [CrossRef] 
5. Heßelbarth, A.; Wanninger, L. SBAS orbit and satellite clock corrections for precise point positioning. GPS Solut. 2013, 17, 465-473. [CrossRef]

6. Li, L.; Jia, C.; Zhao, L.; Cheng, J.; Liu, J.; Ding, J. Real-time single frequency precise point positioning using sbas corrections. Sensors 2016, 16, 1261. [CrossRef]

7. Kim, J.; Lee, Y.J. Using ionospheric corrections from the space-based augmentation systems for low earth orbiting satellites. GPS Solut. 2015, 19, 423-431. [CrossRef]

8. Pungpet, P.; Kitpracha, C.; Promchot, D.; Satirapod, C. Positioning accuracy analyses on GPS single point positioning determination with GAGAN correction services in Thailand. In Proceedings of the 2018 15th International Conference on Electrical Engineering/Electronics, Computer, Telecommunications and Information Technology (ECTI-CON), Chiang Rai, Thailand, 18-21 July 2018; pp. 724-727.

9. Dammalage, T.; De Silva, D.; Satirapod, C. Performance Analysis of GPS Aided Geo Augmented Navigation (GAGAN) Over Sri Lanka. Eng. J. 2017, 21, 305-314. [CrossRef]

10. Marila, S.; Bhuiyan, M.Z.H.; Kuokkanen, J.; Koivula, H.; Kuusniemi, H. Performance comparison of differential GNSS, EGNOS and SDCM in different user scenarios in Finland. In Proceedings of the 2016 European Navigation Conference (ENC), Helsinki, Finland, 30 May-2 June 2016; pp. 1-7.

11. Lopez, M.; Anton, V. SBAS/EGNOS enabled devices in maritime. TransNav Int. J. Mar. Navig. Saf. Sea Transp. 2018, 12, 23-27. [CrossRef]

12. Laurichesse, D.; Privat, A. An open-source PPP client implementation for the CNES PPP-WIZARD demonstrator. In Proceedings of the ION GNSS+ 2015, Tampa, FL, USA, 14-18 September 2015; pp. 2780-2789.

13. Rovira-Garcia, A.; Juan, J.; Sanz, J.; González-Casado, G.; Ibáñez, D. Accuracy of ionospheric models used in GNSS and SBAS: Methodology and analysis. J. Geod. 2016, 90, 229-240. [CrossRef]

14. Bahrami, M.; Ffoulkes-Jones, G.; Zhang, Q. Analysis of SBAS orbit and clock corrections for GPS and their applicability to today's mass market multi-GNSS personal navigation. In Proceedings of the ION GNSS+ 2016, Portland, OR, USA, 12-16 September 2016; pp. 2766-2776.

15. Schmid, R.; Steigenberger, P.; Gendt, G.; Ge, M.; Rothacher, M. Generation of a consistent absolute phase-center correction model for GPS receiver and satellite antennas. J. Geod. 2007, 81, 781-798. [CrossRef]

16. Dach, R.; Schmid, R.; Schmitz, M.; Thaller, D.; Schaer, S.; Lutz, S.; Steigenberger, P.; Wübbena, G.; Beutler, G. Improved antenna phase center models for GLONASS. GPS Solut. 2011, 15, 49-65. [CrossRef]

17. Bar-Sever, Y.E. A new model for GPS yaw attitude. J. Geod. 1996, 70, 714-723. [CrossRef]

18. Kouba, J. A simplified yaw-attitude model for eclipsing GPS satellites. GPS Solut. 2009, 13, 1-12. [CrossRef]

19. Kuang, D.; Desai, S.; Sibois, A. Observed features of GPS Block IIF satellite yaw maneuvers and corresponding modeling. GPS Solut. 2017, 21, 739-745. [CrossRef]

20. Rebischung, P.; Schmid, R. IGS14/igs14. atx: A new framework for the IGS products. In Proceedings of the AGU Fall Meeting 2016, San Francisco, CA, USA, 15 December 2016.

21. FAA. Global Positioning System Wide Area Augmentation System (WAAS) Performance Standard; Federal Aviation Administration (FAA): Washington, DC, USA, 2008.

22. Wong, R.F.; Rollins, C.M.; Minter, C.F. Recent updates to the WGS 84 reference frame. In Proceedings of the ION ITM GNSS 2012, Nashville, TN, USA, 17-21 September 2012; pp. 1164-1172.

23. CNES; ESA; EU. User Guide for EGNOS Application Developers, ED 2.0; European Commission: Brussels, Belgium, 2011.

24. RTCM Special Committee. RTCM Standard 10403.3 Differential GNSS (Global Navigation Satellite Systems) Services, version 3; RTCM Special Committee No. 104: Arlington, TX, USA, 2016.

25. Takasu, T. RTKLIB ver. 2.4. 2 Manual; Tokyo University of Marine Science and Technology: Tokyo, Japan, 2013.

26. Kouba, J.; Héroux, P. Precise point positioning using IGS orbit and clock products. GPS Solut. 2001, 5, 12-28. [CrossRef]

27. Kouba, J. A Guide to Using International GNSS Service (IGS) Products; IGS Central Bureau: Pasadena, CA, USA, 2015.

28. Montenbruck, O; Hauschild, A. Code Biases in Multi-GNSS Point Positioning. In Proceedings of the ION ITM 2013, San Diego, CA, USA, 27-29 January 2013; pp. 616-628.

29. Dach, R.; Lutz, S.; Walser, P.; Fridez, P. Bernese GNSS Software Version 5.2. User Manual; Astronomical Institute, University of Bern, Bern Open Publishing: Bern, Switzerland, 2015.

30. Montenbruck, O.; Steigenberger, P.; Hauschild, A. Broadcast versus precise ephemerides: A multi-GNSS perspective. GPS Solut. 2015, 19, 321-333. [CrossRef] 
31. Heng, L.; Gao, G.X.; Walter, T.; Enge, P. Statistical characterization of GPS signal-in-space errors. In Proceedings of the ION ITM 2011, San Diego, CA, USA, 24-26 January 2011; pp. 312-319.

32. Heng, L. Safe Satellite Navigation with Multiple Constellations: Global Monitoring of GPS and GLONASS Signal-In-Space Anomalies. Ph.D. Thesis, Stanford University, Stanford, CA, USA, 2012.

33. GPS Directorate. Global Positioning System Standard Positioning Service Performance Standard, 4th ed.; Global Positioning System Directorate: Washington, DC, USA, 2008.

34. Brunini, C.; Azpilicueta, F.J. Accuracy assessment of the GPS-based slant total electron content. J. Geod. 2009, 83, 773-785. [CrossRef]

35. Bishop, G.; Klobuchar, J.; Doherty, P. Multipath effects on the determination of absolute ionospheric time delay from GPS signals. Radio Sci. 1985, 20, 388-396. [CrossRef]

36. Mannucci, A.; Wilson, B.; Yuan, D.; Ho, C.; Lindqwister, U.; Runge, T. A global mapping technique for GPS-derived ionospheric total electron content measurements. Radio Sci. 1998, 33, 565-582. [CrossRef]

37. Zhang, Q.; Zhao, Q. Global Ionosphere Mapping and Differential Code Bias Estimation during Low and High Solar Activity Periods with GIMAS Software. Remote Sens. 2018, 10, 705. [CrossRef]

38. Li, Z.; Yuan, Y.; Wang, N.; Hernandez-Pajares, M.; Huo, X. SHPTS: Towards a new method for generating precise global ionospheric TEC map based on spherical harmonic and generalized trigonometric series functions. J. Geod. 2015, 89, 331-345. [CrossRef]

39. Schaer, S. Mapping and Predicting the Earth's Ionosphere Using the Global Positioning System. Ph.D. Thesis, University of Bern, Bern, Switzerland, 1999.

40. Lanyi, G.E.; Roth, T. A comparison of mapped and measured total ionospheric electron content using global positioning system and beacon satellite observations. Radio Sci. 1988, 23, 483-492. [CrossRef]

41. Suard, N.; Gurtner, W.; Estey, L. Proposal for a new RINEX-type Exchange File for GEO SBAS Broadcast Data; UNAVCO: Boulder, CO, USA, 2004.

42. Yousif, H.; El-Rabbany, A. Assessment of several interpolation methods for precise GPS orbit. J. Navig. 2007, 60, 443-455. [CrossRef]

43. Teunissen, P.; Montenbruck, O. Springer Handbook of Global Navigation Satellite Systems; Springer International Publishing AG: Cham, Switzerland, 2017.

44. Klobuchar, J.A. Ionospheric Time-Delay Algorithm for Single-Frequency GPS Users. IEEE Trans. Aerosp. Electron. Syst. 1987, 23, 325-331. [CrossRef]

45. Thomsen, M. Why Kp is such a good measure of magnetospheric convection. Space Weather $2004,2$. [CrossRef]

46. Gonzalez, W.; Joselyn, J.A.; Kamide, Y.; Kroehl, H.W.; Rostoker, G.; Tsurutani, B.; Vasyliunas, V. What is a geomagnetic storm? J. Geophys. Res. Space Phys. 1994, 99, 5771-5792. [CrossRef]

47. Nie, Z.; Yang, H.; Zhou, P.; Gao, Y.; Wang, Z. Quality assessment of CNES real-time ionospheric products. GPS Solut. 2019, 23, 11. [CrossRef]

(C) 2019 by the authors. Licensee MDPI, Basel, Switzerland. This article is an open access article distributed under the terms and conditions of the Creative Commons Attribution (CC BY) license (http:/ / creativecommons.org/licenses/by/4.0/). 